\title{
The Effects of Polypharmacy, Nutritional, Functional Status on the Progression of COVID-19 in Older Adults
}

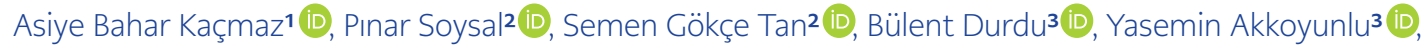

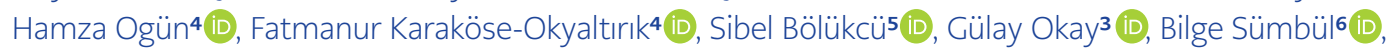

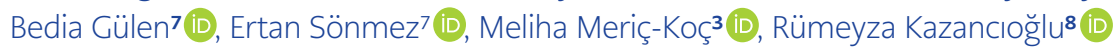

1 Department of Infectious Diseases and Clinical Microbiology, American Hospital, İstanbul, Turkey

2 Department of Geriatric Medicine, Bezmialem Vakıf University School of Medicine, İstanbul, Turkey

3 Department of Infectious Diseases and Clinical Microbiology, Bezmialem Vakıf University School of Medicine, istanbul, Turkey

4 Department of Chest Diseases, Bezmialem Vakıf University School of Medicine, İstanbul, Turkey

5 Department of Infectious Diseases and Clinical Microbiology, Yeditepe University School of Medicine, Istanbul, Turkey

6 Department of Medical Microbiology, Bezmialem Vakıf University School of Medicine, İstanbul, Turkey

7 Department of Emergency Medicine, Bezmialem Vakıf University School of Medicine, İstanbul, Turkey

8 Department of Nephrology, Bezmialem Vakıf University School of Medicine, İstanbul, Turkey

\begin{abstract}
Objective: We aimed to evaluate the effects of nutritional factors, dependence in daily life activities, and polypharmacy on the length of hospitalization, clinical prognosis and mortality among hospitalized older COVID-19 patients.

Materials and Methods: The charts of hospitalized COVID-19 patients older than 60 years old were reviewed retrospectively. We obtained findings on admission, comorbidities and the number of drugs used. The Mini Nutritional Assessment (MNA), the Barthel Index for Activities of Daily Living (BADL) and the Lawton Instrumental Activities of Daily Living (IADL) Scale were used to analyze the findings.

Results: Out of the 73 patients, 39 were female and the mean age was $69.65 \pm 7.39$ years. Fourteen (19.2\%) patients were transferred to the intensive care unit, and nine $(12.3 \%)$ of them died. After adjustment for age, the number of respiration at the first admission was significantly higher $(\mathrm{p}=0.001)$, and BADL, IADL scores and oxygen saturations were significantly lower $(\mathrm{p}=0.00, \mathrm{p}=0.001)$ in the patients transferred to the intensive care unit compared to the patients discharged. There was no association between the length of hospitalization and age, the number of drugs, BADL and IADL scores, but there was a significant negative correlation between the length of hospitalization ( $r$ : -0.310), MNA score ( $r:-0.275)$ and daily protein intake $(\mathrm{p}=0.008)$. No association between polypharmacy and clinical progression of COVID-19 was detected ( $\mathrm{p}=0.109)$.

Conclusion: Decrease in MNA scores and daily protein intake in older COVID-19 patients were associated with prolonged hospitalization. Functional dependence was associated with the need for intensive care and mortality.
\end{abstract}

Keywords: COVID-19, polypharmacy, nutrition, activities of daily living, mortality
Corresponding Author:

Asiye Bahar Kaçmaz

E-mail:

Asybaharkacmaz@hotmail.com

Received: June 25, 2021

Accepted: August 26, 2021

Published: August 31, 2021

\section{Suggested citation:}

Kaçmaz AB, Soysal P, Tan SG, Durdu B, Akkoyunlu Y, Ogün H, et al. The effects of polypharmacy, nutritional and functional status on the progression of COVID-19 in older adults. Infect Dis Clin Microbiol 2021; 2: 70-77.

DOI: $10.36519 / \mathrm{idcm} .2021 .60$ 


\section{INTRODUCTION}

T The SARS-CoV-2 infection has influenced the whole world and every day, both the number of cases and deaths related to the COVID-19 pandemic continue to rise. Eighty-one percent of COVID-19 cases are mild, 14\% are serious and 5\% are critical (1). Although the overall mortality rate was $2.3 \%$, mortality increased exponentially as the age; it is $8.0 \%$ for patients between $70-79$ years old and $14.8 \%$ for $\geq 80$ years old (2). Indeed, in almost all studies on COVID-19, "age" appears to be the most critical risk factor for hospitalization, mortality and intensive care needs $(3,4)$.

Some possible hypotheses about the course of COVID-19 disease among older people were suggested. The first one is based on the changes in the immune system by age. By advancing age, the protective barrier function of the immune system and the structural integrity of the lungs negatively affect pulmonary immunity (5). Moreover, chronic diseases and low levels of inflammatory and proinflammatory cytokines (CRP, TNF-alpha, IL-1 $\beta$, IL-6) in older people may reduce the immune response of the lungs to the epithelial and immune cells against microorganisms $(5,6)$. The decrease in tolllike receptors (TLR) expression, cytokine release and lack of communication between the cells regulating the immune system may bring about worse clinical outcomes in older people (7). The second hypothesis is that delayed diagnosis and treatment because COVID-19 might have atypical presentations such as mental state change, weight loss, and recurrent falls rather than fever and cough. A

\section{HIGHLIGHTS}

- Among older and hospitalized COVID-19 patients, the inability to live independently predicts the need for intensive care treatment and mortality.

- Nutritional impairment of older patients with COVID-19 infection is associated with prolonged hospitalization duration.

- Polypharmacy does not affect the prognosis and mortality of hospitalized older COVID-19 patients. study has reported that older patients with atypical presentations have worse clinical outcomes (8). The third hypothesis is that having comorbidities and drug interactions may negatively affect the prognosis of COVID-19 in older people (9).

Malnutrition, decreased functional capacity and polypharmacy in the course of infectious diseases in older people are strong predictors of mortality and morbidity (10-12). However, more studies are still needed. This study aimed to describe the effects of nutritional factors, dependence in daily life activities, and polypharmacy on hospitalization time, clinical prognosis and mortality among hospitalized older COVID-19 patients.

\section{MATERIALS AND METHODS}

Inclusion of Patients and Diagnosis of COVID-I 9 This is a single-center retrospective study. We followed diagnosis, treatment and follow-up algorithms of the Republic of Turkey Ministry of Health COVID-19 Information Page updated at regular intervals. (13). COVID-19 patients hospitalized and treated between March and May 2020 and confirmed by real-time polymerase chain reaction (RT-PCR) scanned in the oro-nasopharyngeal swab samples were included in the study. RT-PCR was repeated at 24-48 hour intervals in patients who were negative in the initial sample but had lung CT findings suggesting COVID-19 or with clinical suspicion because of high-risk contact.

\section{Exclusion Criteria}

COVID-19 patients $<60$ years of age and possible COVID-19 patients $\geq 60$ years of age (even if CT findings are typical) without RT-PCR positivity were excluded from the study.

\section{Clinical Evaluation Parameters}

On the first admission, symptoms, findings and laboratory tests of the patients with possible COVID-19 infection were recorded. In addition, body temperature, respiratory rate, oxygen saturation, pulse, blood pressure were measured. Based on these measurements, qSOFA and CURB-65 scores were calculated. Concomitant comorbidities, coronary artery disease, congestive heart failure (CHF), chronic kidney disease (CKD), chronic obstructive 
pulmonary disease, cerebrovascular disease, diabetes mellitus, hypertension were questioned and recorded. According to the Republic of Turkey Ministry of Health COVID-19 Information Page algorithms, each patient underwent a standardized treatment (13). Hospital stay, intensive care needs and mortality numbers of the patients monitored under treatment were recorded.

Polypharmacy: Drugs used regularly by the patients were recorded, and $\geq 5$ drug use was accepted as polypharmacy (14).

Nutritional status assessment: The Mini Nutritional Assessment (MNA) was applied to assess the nutritional status of the patients before the onset of COVID-19 related symptoms. MNA consists of four parts: anthropometric measurements (four questions related to body mass index, weight loss, mid-arm circumference, and calf circumference), global assessment (six questions related to lifestyle, medication, and mobility), dietary assessment (six questions related to the number of meals, protein, fruit/vegetables and fluid intake, and autonomy of feeding), and subjective assessment (two questions related to self-perception of health and nutrition status). The total score is the sum of screening and assessment scores and ranges from 0 to 30 points. If the total score was $>23.5$, it was considered that there was no malnutrition; if it was $\leq 23.5$, deteriorated nutrition (risk of malnutrition, or malnutrition) was considered (15).

Evaluation of functionality: The Barthel Index for Activities of Daily Living (BADL) and the Lawton Instrumental Activities of Daily Living (IADL) Scale were used to evaluate the functional independence of patients before COVID-19. BADL includes ten personal activities: feeding, personal toileting, bathing, dressing and undressing, getting on and off a toilet, controlling the bladder, controlling bowel, moving from wheelchair to bed and returning, walking on a level surface (or propelling a wheelchair if unable to walk). While 100 points show complete independence, 0 (zero) indicates full dependence (16). IADL can be used to determine the patient's independence in daily life routine activities (using phones, transportation, shopping, preparing meals, daily household chores, laundry, recognizing and using drugs, and money management). Scoring from 0 to 2-4 is done for each activity. The total score ranges from 0 to 23, and the lower the score, the higher the dependency (17).

\section{Statistical Analysis}

Data analysis was performed by the Statistical Package for Social Sciences (SPSS) version 17.0 for Windows (SPSS Inc., Chicago, IL). Descriptive statistics are reported as mean \pm standard deviation, and the number of cases and percentage (\%) for nominal variables. Demographic characteristics of participants were analyzed using descriptive statistics. The significance of differences between the groups in terms of averages was investigated by t-test and median values by the Mann-Whitney U test. When the number of groups was more than two, the significance of differences between the groups in terms of averages was investigated by the ANOVA test, post hoc ANOVA test and the significance was determined by the Kruskal-Wallis test. Nominal variables were assessed by Pearson's chi-square or Fisher's exact test. Spearman's correlation was performed to reveal if the length of hospital stay is associated with age, the scores of BADL, IADL, MNA and number of drugs. Binary logistic regression analysis was made for age, and analysis was performed for factors that might affect intensive care requirement and survival. Statistical significance was set as $\mathrm{p}<0.05$.

The study design and all procedures performed in studies involving human participants were in accordance with the ethical standards of the institutional and national research committee.

\section{RESULTS}

Out of PCR (+) 503 patients, 103 were over 60. Seventy-three patients without missing data were included in the study. Out of 73 patients, 39 (53.4\%) were female, 34 (46.6\%) were male, and the mean age was 69.65 (sd: 7.39) years. The most common comorbidities were hypertension (63\%), diabetes mellitus (28.8\%), chronic heart disease $(28.8 \%)$ and chronic obstructive pulmonary disease (23.3\%). The most common symptoms on admission were cough $(64.4 \%)$, fatigue (56.2\%), fever (35.6\%), and dyspnea (30.1\%). Among all symptoms, dyspnea was asso- 
ciated with mortality and intensive care treatment $(p<0.05)$. Polypharmacy was detected in $28.8 \%$ of the patients. The nutritional status of 16 patients $(22 \%)$ was impaired. At least one dependent in BADL and in IADL was $41.1 \%$ and $45.2 \%$, respectively (Table 1 ).

Fourteen patients were followed up in the intensive care unit, and nine of them died. Age, the presence of CHF and CKD, the number of respiration and pulse at the first admission, qSOFA and CURB-65 scores were significantly associated with being in ICU and fatality $(p<0.05)$. BADL and IADL scores and oxygen saturations were found to be significantly lower $(p<0.05)$. After adjustment for age, the number of respiration, BADL and IADL scores were still significant for being in ICU and fatality $(p<0.05)$ (Table 2).

There was no difference in terms of MNA scores, but when looking at the clinical outcome with each question of MNA, it was found that only the one "living independently" was significantly different. It was determined that $88.9 \%$ of those who died and $71.4 \%$ of those in need of intensive care could not live independently before contracting COVID-19 $(\mathrm{p}<0.001)$.

No association was detected between hospitalization duration and age, the number of drugs, BADL and IADL scores, but significant negative correlation between hospitalization duration and "MNA score and daily protein intake (a question of MNA)" ( $r$ : -0.310 and $r:-0.275$, respectively; $p<0.05$ ). In addition, a positive correlation was found between hospital stay and hospital respiration rate ( $r$ : 0.337, $\mathrm{p}<0.05)$ and a negative correlation with oxygen saturation ( $r:-0.273, p<0.05)$.

There was no relationship between polypharmacy and clinical progression of COVID-19 ( $p>0.05)$.

\section{DISCUSSION}

We detected that among older people with hospitalized COVID-19, low BADL, IADL scores, and inability to live independently predict the need for intensive care treatment and mortality. In addition, it was determined that there was a relationship between prolonged hospital stay, decreased MNA
Table 1. Characteristics of the patients.

\begin{tabular}{|c|c|}
\hline & $n=73(\%)$ \\
\hline Age & 69.65 (sd:7.39) \\
\hline Gender (female/male) & $39 / 34$ \\
\hline \multicolumn{2}{|l|}{ Symptomes } \\
\hline Cough & $47(64.4)$ \\
\hline Fatigue & $41(56.2)$ \\
\hline Fever & $26(35.6)$ \\
\hline Dyspnoea & $30(30.1)$ \\
\hline Nausea & $18(24.7)$ \\
\hline Anorexia & $12(16.4)$ \\
\hline Vomiting & $11(15.1)$ \\
\hline Sore throat & $8(11.0)$ \\
\hline Headache & $6(8.2)$ \\
\hline Myalgia & $5(6.8)$ \\
\hline Diarrhea & $4(5.5)$ \\
\hline Chest Pain & $3(4.1)$ \\
\hline Anosmia & $3(4.1)$ \\
\hline Back pain & $3(4.1)$ \\
\hline Sweating & $3(4.1)$ \\
\hline Mental changes & $2(2.7)$ \\
\hline \multicolumn{2}{|l|}{ Comorbidities (\%) } \\
\hline HT & $46(63.0)$ \\
\hline DM & $21(28.8)$ \\
\hline CAD & $21(28.8)$ \\
\hline COPD & $17(23.3)$ \\
\hline $\mathrm{CHF}$ & $10(13.7)$ \\
\hline CKD & $8(11.0)$ \\
\hline CVD & $2(2.79)$ \\
\hline Polypharmacy & $21(28.8)$ \\
\hline Number of drugs & 3.46 (sd:2.87) \\
\hline MNA & 24.94 (sd:3.14) \\
\hline BADL & 92.66 (sd:18.15) \\
\hline IADL & 19.36 (sd:6.38) \\
\hline
\end{tabular}

BADL: The Barthel Index for Activities of Daily Living;

IADL: The Lawton Instrumental Activities of Daily Living Scale; CAD: Coronary Artery Disease;

CHF: Congestive Heart Failure; CKD: Chronic Kidney Disease; COPD: Chronic Obstructive Pulmonary Disease;

CVD: Cerebrovascular Disease; DM: Diabetes Mellitus;

HT: Hypertension; MNA: The Mini Nutritional Assessment 
Table 2. The comparison the patients who were transferred to intensive care/ex and discharged from the hospital.

\begin{tabular}{|c|c|c|c|c|c|c|}
\hline & $\begin{array}{c}\text { Intensive care } \\
\text { unit }(+) \\
n=14(\%)\end{array}$ & $\begin{array}{c}\text { Intensive care } \\
\text { unit }(-) \\
n=59(\%)\end{array}$ & $\mathbf{P}$ & Fatal $n=9(\%)$ & $\begin{array}{l}\text { Survived } \\
n=64(\%)\end{array}$ & $\mathrm{p}$ \\
\hline Age & 74.5 (sd:9.3) & 68.51 (sd:6.44) & 0.029 & 79.67 (sd:5.72) & 68.25 (sd:6.48) & $<0.001$ \\
\hline Female/male & $5 / 9$ & $34 / 25$ & 0.139 & $4 / 5$ & $35 / 29$ & 0.564 \\
\hline \multicolumn{7}{|l|}{ Physical examination } \\
\hline Body temperature $\left(\geq 37.5^{\circ} \mathrm{C}\right)$ & $5(35.7)$ & $21(35.5)$ & 0.993 & $3(33.33)$ & $23(35.93)$ & 0.879 \\
\hline $\begin{array}{l}\text { Mean blood pressure } \\
\text { (min-max) }\end{array}$ & $\begin{array}{l}137.71(\mathrm{sd}: 31.8) \\
73.86 \text { (sd:15.7) }\end{array}$ & $\begin{array}{l}138.11 \text { (sd:20.72) } \\
77.75 \text { (sd:12.55) }\end{array}$ & $\begin{array}{c}0.536 \\
0.17\end{array}$ & $\begin{array}{c}137.67 \text { (sd:31.77) } \\
73.11 \text { (sd:16.92) }\end{array}$ & $\begin{array}{l}138.08 \text { (sd:21.86) } \\
77.54 \text { (sd:12.64) }\end{array}$ & $\begin{array}{l}0.812 \\
0.204\end{array}$ \\
\hline Mean pulse & 100.64 (sd:17.51) & 88.47 (sd:13.65) & 0.019 & 103.67 (sd:18.92) & 89 (sd:13.75) & 0.021 \\
\hline Mean respiratory rate & 22 (sd:2.94) & 18.64 (sd: 1.6) & $<0.001^{*}$ & 21.56 (sd:2.79) & 18.97 (sd: 2.09) & $0.005^{*}$ \\
\hline Mean saturation & 90 (sd:5.39) & 94.34 (sd:4.95) & $<0.001^{*}$ & 89.67 (sd:6.58) & 94.05 (sd:4.9) & $0.028^{*}$ \\
\hline qSOFA & 1.07 (sd:0.26) & 1.01 ( sd:0.13) & 0.322 & 1.11 (sd:0.33) & 1.01 (sd:0.12) & 0.42 \\
\hline CURB-65 & 1.64 (sd:0.63) & 1.32 (sd:0.5) & $<0.05$ & 2 (sd:0.5) & 1.29 (sd:0.49) & $<0.05$ \\
\hline \multicolumn{7}{|l|}{ Comorbidities } \\
\hline HT & $9(64.2)$ & $37(62.7)$ & 0.773 & $5(55.55)$ & $41(64.06)$ & 0.646 \\
\hline DM & $4(28.5)$ & $17(28.81)$ & 0.986 & $2(22.22)$ & $19(29.68)$ & 0.643 \\
\hline CAD & $6(42.8)$ & $15(25.4)$ & 0.207 & $4(44.44)$ & $17(26.56)$ & 0.267 \\
\hline $\mathrm{CHF}$ & $5(35.7)$ & $5(8.47)$ & 0.019 & $4(44.44)$ & $6(9.37)$ & 0.017 \\
\hline COPD & $3(21.4)$ & $8(13.5)$ & 0.431 & $2(22.22)$ & $9(14.06)$ & 0.617 \\
\hline CKD & $4(28.5)$ & $3(5.08)$ & 0.005 & $5(55.55)$ & $3(4.68)$ & $<0.001$ \\
\hline CVD & $1(7.1)$ & $1(1.69)$ & 0.349 & $1(11.11)$ & $1(1.56)$ & 0.233 \\
\hline \multicolumn{7}{|l|}{ Geriatric assessment } \\
\hline BADL & 80.71 (sd:27.39) & 95.49 (sd:14.09) & $0.001^{*}$ & 73.89 (sd:30.82) & 95.3 (sd:14.10) & $<0.001^{*}$ \\
\hline MNA & 23.96 (sd:3.99) & 25.17 (sd:2.9) & 0.231 & 23.17 (sd:3.73) & 25.19 (sd:3) & 0.071 \\
\hline IADL & 14.07 (sd:8.1) & 22.61 (sd:5.24) & $0.001^{*}$ & 10.44 (sd:7.58) & 20.61 (sd: 5.13) & $<0.001^{*}$ \\
\hline Number of drugs & 4.36 (sd:3.1) & 3.19 (sd:2.81) & 0.17 & 5.11 (sd:3.33) & 3.17 (sd:2.76) & 0.084 \\
\hline Polypharmacy (\%) & $6(42.9)$ & $14(23.7)$ & 0.187 & $4(44.4)$ & $16(25.0)$ & 0.246 \\
\hline
\end{tabular}

BADL: The Barthel Index for Activities of Daily Living; IADL: The Lawton Instrumental Activities of Daily Living Scale; CAD: Coronary Artery Disease; CHF: Congestive Heart Failure; CKD: Chronic Kidney Disease; COPD: Chronic Obstructive Pulmonary Disease; CVD: Cerebrovascular Disease; DM: Diabetes Mellitus; HT: Hypertension; MNA: The Mini Nutritional Assessment; *After adjustment for age, the values are still significant. 
score and decreased protein intake. Polypharmacy had no negative effect on the course of COVID-19. Advanced age, increased respiratory rate at the time of admission, and low oxygen saturation level can also predict the adverse clinical progression of COVID-19.

It has been found that atypical presentations are frequently seen in the studies of COVID-19 in elderly patients, in which clinical characteristics of admission were evaluated (18). In our study, the symptoms of fever, cough and dyspnea at the time of admission, which were considered typical for COVID-19, were $35.6 \%, 64.4 \%$ and $30.1 \%$, respectively. This situation suggests that questioning only these symptoms in older people may lead to delayed diagnosis. Furthermore, we found that fatigue was reported in one of both patients; the presence of atypical symptoms such as nausea, vomiting, decreased appetite were frequently reported. In the study conducted by Zhao et al., the symptoms of admission were analyzed according to age groups, and it was shown that with increasing age $(\geq 75$ years), fever complaints decreased and dyspnea increased (18). These results may show that since older people do not develop symptoms such as cough and fever, complaints of dyspnea are more prominent, indicating that hospital admissions are delayed and that when they present to the hospital, they have already lung involvement. In this study, the fact that dyspnea during the admission of the older people to the hospital, the high number of respiration, which is one of the first physical examination findings, and low oxygen saturation are associated with poor clinical course supports this hypothesis (hospitalization and death in intensive care).

On the other hand, in this study, low MNA scores before COVID-19 infection and decreased daily protein intake were associated with prolonged hospitalization duration. Indeed, previous studies have shown that coronavirus increases the risk of hospitalization four times higher in patients with undernutrition than respiratory viruses such as parainfluenza virus compared to those with normal nutrition (19). This may have several possible causes: First, nutritional impairment with advanced age causes functional and structural impairment in all organ systems, primarily cardiorespiratory and musculoskeletal (20). Second, nutritional status exerts a relevant impact on the immune system of older people through impairment in cell-mediated immunity, cytokine production and phagocytic function (21). Third, decreased protein consumption can lead to low muscle mass and low muscle strength, causing sarcopenia. Sarcopenia is highly prevalent in older adults and associated with a higher risk of pneumonia, indicating generalized muscle strength loss, including respiratory and oropharyngeal muscles (22). In our study, a low MNA score was found to be related to the prolonged hospitalization duration. For this reason, patients both during their first hospitalization and during their stay should be regularly reviewed in terms of nutrition and supported with protein-rich dietary supplements.

We did not detect the effect of the number of drugs used by the patients on the prognosis of COVID-19. However, polypharmacy and drug-drug interactions are observed commonly in older adults (23). Therefore, when hydroxychloroquine, in particular, is combined with antihypertensives, antidepressants, and antipsychotic drugs used in the treatment of COVID-19, the development of side effects may arise; for example, it may increase the risk of developing arrhythmia by extending the QT distance (24). However, we reviewed polypharmacy, but not drug-drug interaction.

The limitation of our study is being retrospective, cross-sectional, and having a low sample size. However, the findings among older patients could be useful in clinical practice.

In conclusion, a decrease in MNA scores and daily protein intake was associated with prolonged hospitalization in older COVID-19 patients; functional dependence was associated with being in ICU and mortality. Therefore, the nutritional status and daily activities should be evaluated when an older adult is admitted to the hospital because of COVID-19 infection. Thus, clues may be obtained about which patients should be followed up with close monitoring. Furthermore, the same parameters should be checked regularly during the hospital stay and appropriate supplements should be made. 
Ethical Approval: The Ethics Committee of Bezmialem Vaklf University approved the study with the decision number of 202006/110.

Informed Consent: This is a retrospective study for which no formal consent is required.

Peer-review: Externally peer-reviewed

Author Contributions: Concept - A.B.K., P.S., S.G.T., B.D., Y.A., H.O., F.K.O, S.B., G.O., B.S., B.G., E.S., M.M.K, R.K.; Design - A.B.K., P.S., S.G.T., B.D., Y.A., H.O., F.K.O, S.B., G.O., B.S., B.G., E.S., M.M.K, R.K.; Supervi- sion - A.B.K., P.S., S.G.T., B.D., Y.A., H.O., F.K.O, S.B., G.O., B.S., B.G., E.S., M.M.K, R.K.; Findings - A.B.K., P.S., M.M.K., R.K.; Materials - A.B.K., P.S., M.M.K., R.K.; Data Collection and/or Processing - A.B.K., S.G.T., B.D., Y.K., S.B.; Analysis and/or Interpretation - A.B.K., P.S., M.M.K, R.K.; Literature Review - A.B.K., P.S., M.M.K, R.K.; Writer - A.B.K., P.S., M.M.K, R.K.; Critical Reviews - A.B.K., P.S., M.M.K, R.K.

Conflict of Interest: The authors have no conflict of interest to declare.

Financial Disclosure: The authors declared that this study has received no financial support.

\section{REFERENCES}

1 Wang L, Wang Y, Ye D, Liu Q. Review of the 2019 novel coronavirus (SARS-CoV-2) based on current evidence. Int J Antimicrob Agents. 2020;55(6):105948. [CrossRef]

2 Wu Z, McGoogan JM. Characteristics of and important lessons from the coronavirus disease 2019 (COVID-19) outbreak in China: Summary of a report of 72314 cases from the Chinese Center for Disease Control and Prevention. JAMA. 2020;323(13):1239-42. [CrossRef]

3 Stokes EK, Zambrano LD, Anderson KN, Marder EP, Raz KM, Felix SEB, et al. Coronavirus disease 2019 case surveillance United States, January 22-May 30, 2020. MMWR Morb Mortal Wkly Rep. 2020;69(24):759-65. [CrossRef]

4 Liu K, Chen Y, Lin R, Han K. Clinical features of COVID-19 in elderly patients: A comparison with young and middle-aged patients. J Infect. Jun, 2020;80(6):e14-e18. [CrossRef]

5 Miller EJ, Linge HM. Age-related changes in immunological and physiological responses following pulmonary challenge. Int J Mol Sci. 2017;18(6):1294. [CrossRef]

6 Boe DM, Boule LA, Kovacs EJ. Innate immune responses in the ageing lung. Clin Exp Immunol. 2017;187(1):16-25. [CrossRef]

7 Nikolich-Zugich J, Knox KS, Rios CT, Natt B, Bhattacharya D, Fain MJ. SARS-CoV-2 and COVID-19 in older adults: what we may expect regarding pathogenesis, immune responses, and outcomes. Geroscience. Apr, 2020;42(2):505-514. [CrossRef]

8 Hofman MR, van den Hanenberg F, Sierevelt IN, Tulner CR. Elderly patients with an atypical presentation of illness in the emergency department. The Neth J Med. 2017;75(6):241-6.

9 Iaccarino G, Grassi G, Borghi C, Ferii C, Salvetti M, Volpe M, et al. Age and multimorbidity predict death among COVID-19 patients: Results of the SARS-RAS study of the Italian Society of Hypertension. Hypertension. 2020;76(2):366-72. [CrossRef]

10 Frazier SC. Health outcomes and polypharmacy in elderly individuals: an integrated literature review. J Gerontol Nurs. 2005;31(9):4-11. [CrossRef]

11 Byun S-E, Shon H-C, Kim JW, Kim HY, Sim Y. Risk factors and prognostic implications of aspiration pneumonia in older hip fracture patients: A multicenter retrospective analysis. Geriatr Gerontol Int. 2019;19(2):119-23. [CrossRef]
12 Bousquet G, Falgarone G, Deutsch D, Derolez S, Lopez-Sublet M, Goudot FX, et al. ADL-dependency, D-Dimers, LDH and absence of anticoagulation are independently associated with one-month mortality in older inpatients with Covid-19. Aging (Albany NY). Jun 23, 2020;12(12):11306-13. [CrossRef]

13 T.C. Sağlık Bakanlığı COVID-19 Bilgilendirme Platformu [Internet]. (cited June 25, 2021). Turkish. Available from: https:// covid19bilgi.saglik.gov.tr/tr

14 Jyrkkä J, Enlund H, Korhonen MJ, Sulkava R, Hartikainen S. Polypharmacy status as an indicator of mortality in an elderly population. Drugs Aging. 2009;26(12):1039-48. [CrossRef]

15 Kalan U, Arik F, Isik AT, Soysal P. Nutritional profiles of older adults according the Mini-Nutritional Assessment. Aging Clin Exp Res. 2020;32(4):673-680. [CrossRef]

16 Mahoney FI, Barthel DW. Functional Evaluation: The Barthel Index. Md State Med J. 1965;14:61-5.

17 Lawton MP, Brody EM. Assessment of older people: self-maintaining and instrumental activities of daily living. Gerontologist. 1969;9(3):179-86.

18 Zhao M, Wang M, Zhang J, Gu J, Zhang P, Xu Y, et al. Comparison of clinical characteristics and outcomes of patients with coronavirus disease 2019 at different ages. Aging (Albany NY). 2020;12(11):10070-86. [CrossRef]

19 Kojima G. Frailty as a predictor of disabilities among community-dwelling older people: a systematic review and meta-analysis. Disabil Rehabil. Sep, 2017;39(19):1897-908. [CrossRef]

20 Jeon K, Yoo H, Jeong BH, Park HY, Koh WJ, Suh GY, et al. Functional status and mortality prediction in community-acquired pneumonia. Respirology. 2017;22(7):1400-6. [CrossRef]

21 Rivera-Izquierdo M, del Carmen Valero-Ubierna M, R-delAmo JL, Fernández-García MÁ, Martínez-Diz S, Tahery-Mahmoud A, et al. Sociodemographic, clinical and laboratory factors on admission associated with COVID-19 mortality in hospitalized patients: A retrospective observational study. PLoS ONE. 2020;15(6):e0235107. [CrossRef]

22 Moser JS, Galindo-Fraga A, Ortiz-Hernández AA, Gu W, Hunsberger S, Galán-Herrera JF, Guerrero ML, Ruiz-Palacios GM, Beigel JH; La Red ILI 002 Study Group. Underweight, 
overweight, and obesity as independent risk factors for hospitalization in adults and children from influenza and other respiratory viruses. Influenza Other Respir Viruses. Jan, 2019;13(1):3-9. [CrossRef]

23 Bencivenga L, Rengo G, Varricchi G. Elderly at time of COronaVIrus disease 2019 (COVID-19): possible role of immunosenescence and malnutrition. GeroScience. 2020;42(4):108992. [CrossRef]

24 Lidoriki I, Frountzas M, Schizas D. Could nutritional and functional status serve as prognostic factors for COVID-19 in the elderly? Med Hypotheses. 2020;144:109946. [CrossRef]

25 Altuna-Venegas S, Aliaga-Vega R, Maguiña JL, Parodi JF, Runzer-Colmenares FM. Risk of community-acquired pneumonia in older adults with sarcopenia of a hospital from Callao, Peru 2010-2015. Arch Gerontol Geriatr. 2019;82:100-5. [CrossRef]
26 Unutmaz GD, Soysal P, Tuven B, Isik AT. Costs of medication in older patients: before and after comprehensive geriatric assessment. Clin Interv Aging. Apr 9, 2018;13:607-13. [CrossRef]

27 Sapp JL, Alqarawi W, MacIntyre CJ, Tadros R, Steinberg C, Roberts JD, et al. Guidance on minimizing risk of drug-induced ventricular arrhythmia during treatment of COVID-19: A statement from the Canadian Heart Rhythm Society. Can J Cardiol. Jun, 2020;36(6):948-51. [CrossRef] 